\title{
VALE DE CHÃO 1, BRAGA. UM TUMULUS DA IDADE DO BRONZE NO NOROESTE PORTUGUÊS
}

\author{
LUCIANO VILAS BOAS ${ }^{(1)}$
}

Resumo:

Este artigo pretende dar a conhecer os resultados obtidos nos trabalhos arqueológicos efetuados no monumento funerário de Vale de Chão 1, estrutura tumular fundada no Bronze Inicial e reutilizada no Bronze Médio, localizada na freguesia de Pedralva, concelho de Braga. Este monumento apresenta um peculiar interesse na medida em que evidencia uma eventual reutilização por inumação efetuada no seu tumulus, durante o último período referido. Este facto sugere que o lugar foi usado e reutilizado na longa duração. De destacar, ainda, a localização do monumento e as sua interação com o espaço que o rodeia.

Palavras-chave: Idade do Bronze Inicial e Médio, Arquitetura funerária, Materiais de construção, Reutilização, Práticas funerárias.

\begin{abstract}
:
Vale de Chão 1, Braga. A Bronze Age tumulus in Northwestern Portugal.

This paper intends to expose the data obtained during an archaeological work carried out in the funerary monument of Vale de Chão 1, sepulchral structure founded the Early Bronze and reused in the Middle Bronze, located in the village of Pedralva, municipality of Braga. This tomb present a particular interest, in that, it shows an inhumation for reuse in a subsequent period Bronze Age. This fact suggests that this place was used and reused in the long diachrony. It is noteworthy the location of the monument and its interaction with the space surrounding it.
\end{abstract}

Keywords: Early and Middle Bronze Age; Burial architectures, Construction materials, Reuse, Burial pratices.

Received: 17 December2013; Accepted: 23 February, 2014

\section{INTRODUÇÃO}

A descoberta e a primeira escavação do monumento 1 de Vale de Chão ocorreu em Maio de 2007, no decorrer dos trabalhos arqueológicos efetuados por Luís Filipe Loureiro no âmbito da empreitada "Desvio da Linha Aérea Alto Lindoso - Riba D’Ave 1, a partir do apoio P101 para a Subestação de Pedralva", adjudicada à empresa Nova Arqueologia - Arqueologia, Informática e Serviços, $\mathrm{Lda}^{1}$.

Após a intervenção arqueológica, aprovada pela tutela, várias questões ficaram por resolver: a delimitação do perímetro total do tumulus; a tipologia da câmara funerária; a cronologia da sua fundação; o significado das irregularidades observáveis na couraça lítica superficial, localizadas a noroeste e a funcionalidade e cronologia de um pequeno valado existente sob o monumento. Com o objetivo de dar resposta às questões anteriores e de aumentar os conhecimento sobre os contextos e as práticas funerárias da Pré-história Recente do Noroeste de Portugal considerámos a realização de novas escavações arqueológicas nesta estrutura, bem como a sua contextualização cultural e espacial. Elaborámos, assim, o projeto intitulado “ $\mathrm{O}$
Povoamento Pré-histórico da Serra do Carvalho. Estudo a partir dos tumulus 1 e 2 de Vale de Chão, Braga", submetido ao IGESPAR, que se articula com a dissertação de mestrado que desenvolvemos na Universidade do Minho. Neste âmbito procedemos a novas campanhas de escavação nesta estrutura cujos resultados constituem o objetivo deste artigo

\section{LOCALIZAÇÃO ADMINISTRATIVA E CONTEXTO FÍSICO E AMBIENTAL MONUMENTO}

Vale de Chão localiza-se no distrito e concelho de Braga, freguesia de Pedralva, lugar das Eiras. As coordenadas geográficas em graus decimais, no sistema WGS 84, são: 41ㄷ5739 N; Longitude: $-8^{\circ} 3249$ W. A altitude a que se encontra o tumulus é de $440 \mathrm{~m}$.

$\mathrm{O}$ monumento implanta-se numa pequena plataforma alongada no sentido NO-SE, a meio da vertente sul da Serra do Carvalho. Esta plataforma é ladeada por dois cursos de água sazonais que alimentam a ribeira de Reamondes, afluente do rio da Veiga, pertencente à bacia hidrográfica do Ave. A sul deste local existe um

\footnotetext{
(1) Mestrando em Arqueologia na Universidade do Minho, Departamento de História, Instituto de Ciências Sociais, Campus de Gualtar, 4710-057, Braga. Email: lucianomvb@gmail.com

Agradecemos a Luís Loureiro a consulta do seu relatório de escavação apresentado e aprovado pelo Igespar (LOUREIRO, L.F. 2007. Desvio da Linha Aérea Alto do Lindoso - Riba D'Ave 1, a partir do Apoio P101 para a Subestação de Pedralva. Braga: Nova Arqueologia Lda.).
} 
pequeno alvéolo granítico, alongado, onde corre a referida ribeira que é, atualmente, alvo de intensas práticas agrícolas (Fig. 1).

Segundo a Carta Geológica de Portugal, folha 5D, na escala 1:50000 e a sua respetiva notícia explicativa (FERREIRA et al. 2000a, 2000b), o substrato local é formado por granitos porfiroides de grão grosseiro a médio e médio a fino. Apesar de não constarem da referida Carta Geológica existem no local ocorrências de quartzo leitoso. A cerca de $4 \mathrm{~km}$ para nascente ocorrem locais de contacto entre granito e o xisto, onde se registam recursos mineralógicos, nomeadamente estanho.

O eucalipto é a árvore predominante da área, embora na envolvência do túmulo existam alguns carvalhos, pinheiros e sobreiros. A vegetação que o envolvia era arbustiva e herbácea.

O local é, ainda hoje, usado para a pastorícia, embora no vale da ribeira de Reamondes existam campos agrícolas.

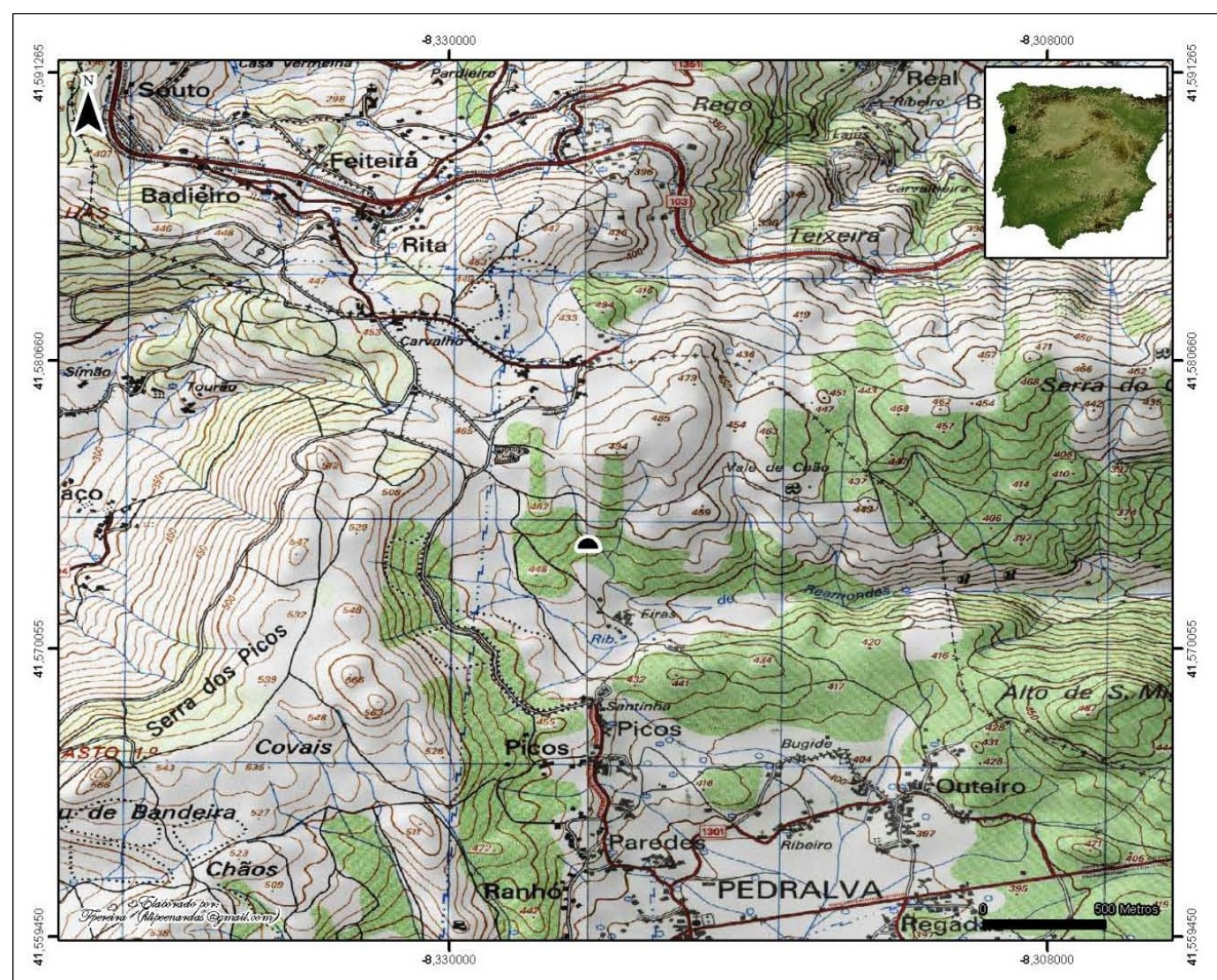

Fig. 1. Localização nas Cartas Militares de Portugal, 56 (1997) e ${ }^{0} 57$ (1998) do monumento sob tumulus de Vale de Chão 1.

Fig. 1. Location of the Vale de Chão burial context at the Militar Charts of Portugal no 56 (1997) and no57 (1998).

\section{RESULTADOS DA ESCAVAÇÃO}

\subsection{Introdução}

As primeiras escavações realizadas neste monumento por Luís Loureiro consistiram na abertura de duas valas de sondagem: uma orientada a oeste e outra a sul, com quadrados de $1 \mathrm{~m}^{2}$. A primeira sondagem compreendeu a escavação dos quadrados E-1, E0, E1, E2 e E3. A segunda, abarcou os quadrados E4, D4, C4 e B4. Na área que foi entendida como zona central do monumento foram abertos mais dois quadrados: F2 e F3.

As novas campanhas de escavação verificaram-se entre 2009 e 2010 e alargaram consideravelmente a área intervencionada anteriormente. Estas implicaram a escavação de quatro áreas, a saber: alargamento da área central, sondagem noroeste, sondagem norte e sondagem este.

$\mathrm{Na}$ zona central foram terminados os quadrados F2, F3 e E4, escavados parcialmente por Luís Loureiro, e abertos os quadrados E5, F4, F5. Esta área foi alargada com o objetivo de se identificar uma eventual câmara funerária.

Nas escavações de 2007 foi detetado, nos quadrados F2 e F3, aquilo que nos parecia ser uma estrutura em negativo, aberta nas terras do tumulus. A perturbação parcial da couraça nos quadrados G2, G3 e G4 parecia corroborar esta hipótese, o 
que nos levou a intervencionar estes quadrados, que denominámos de sondagem noroeste.

A sondagem norte e este tiveram por objetivo aferir os limites do monumento para que se pudesse ter a perceção da sua real dimensão. A sondagem norte comportou os quadrados I5 e J5. A sondagem este, que ultrapassou a delimitação do monumento, foi aberta com o objetivo de aferir, por um lado, o limite da couraça pétrea e, por outro, de verificar a existência ou não de outras estruturas nesta zona limítrofe do monumento. Esta sondagem compreendeu os quadrados D7,
E7, E8, E9, E10, F7, F8, F9, F10, G7, G8, G9 e G10.

Tendo em conta os objetivos enunciados efetuou-se uma decapagem do monumento, tendo sido usada uma malha quadricular orientada a norte, com quadrados de $1 \mathrm{~m}^{2}$. A escavação seguiu as camadas resultantes da deposição dos sedimentos que constituem o tumulus. Assim, nas duas campanhas foram abertas quatro sanjas: a este, a oeste, a norte e a sul; uma sondagem a noroeste e a área central, num total de $35 \mathrm{~m}^{2}$ (Fig. 2).

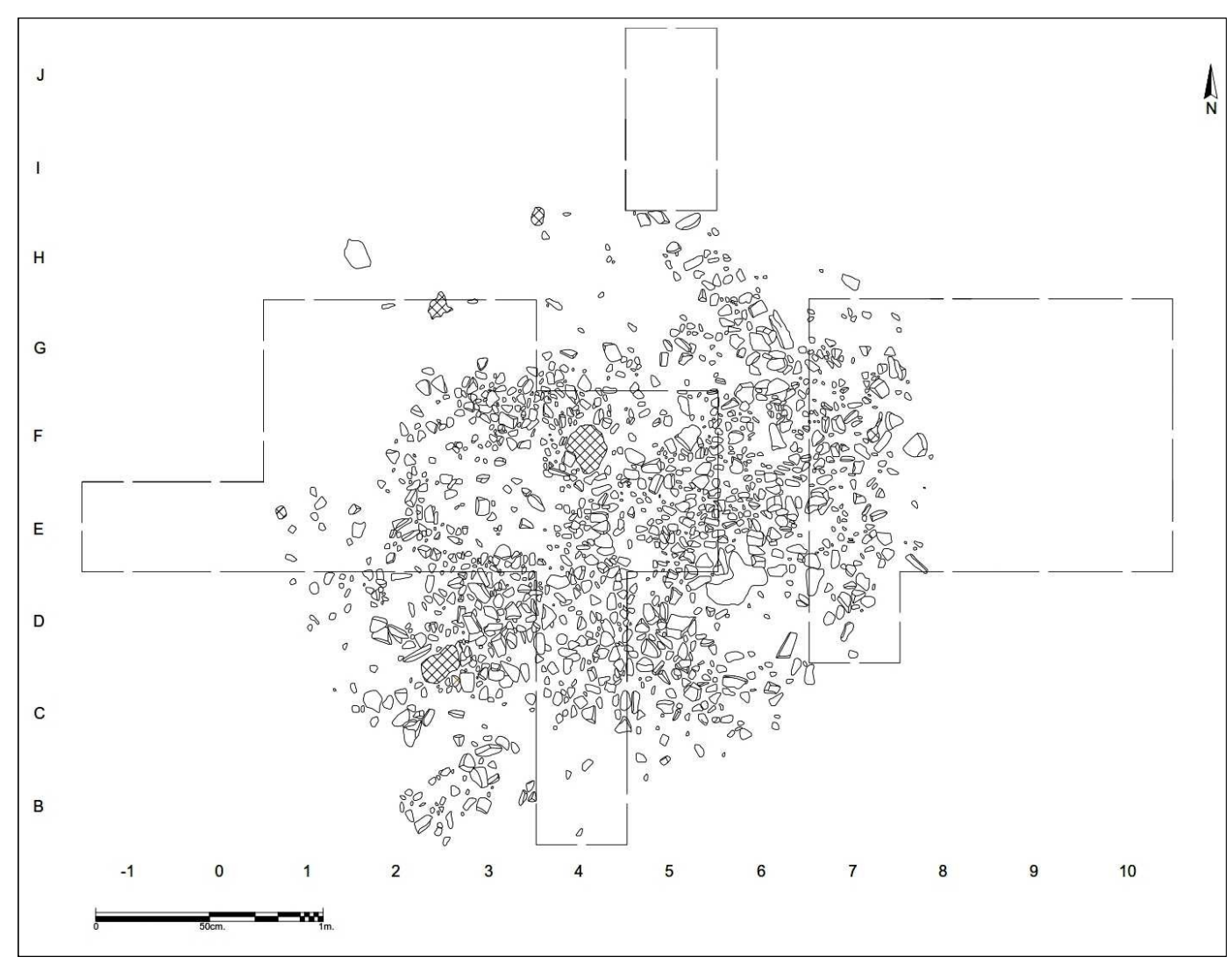

Fig. 2. Planta do monumento após a decapagem inicial com a localização de todas as sondagens arqueológicas aí realizadas. Fig. 2. Plan of the monument after the initial cleaning with the location of all archaeological surveys carried out.

Foi efetuada a crivagem de sedimentos extraídos da área central do monumento, bem como da estrutura aberta no tumulus, posteriormente à sua construção (estrutura 1), com o intuito de recolhermos elementos passíveis de serem datados, como por exemplo, fragmentos de carvão vegetal ou humano ou ossos, apesar destes últimos serem de difícil conservação em solos graníticos. Sempre que necessário, foram efetuados registos gráficos (planos e perfis) à escala $1 / 20$, e fotografias com e sem escala. O ponto "0" adotado para esta escavação localiza-se no apoio nordeste do poste de alta tensão aqui existente, por ser uma estrutura estável.

\subsection{Estruturas}

As sondagens norte, sul, este e oeste permitiram verificar que esta estrutura funerária era constituída por um montículo de c. de $7 \mathrm{~m}$ de diâmetro, em cuja base foram depositados sedimentos e no topo uma couraça pétrea composta por calhaus e por blocos de granito e de quartzo leitoso (Fig. 3). 


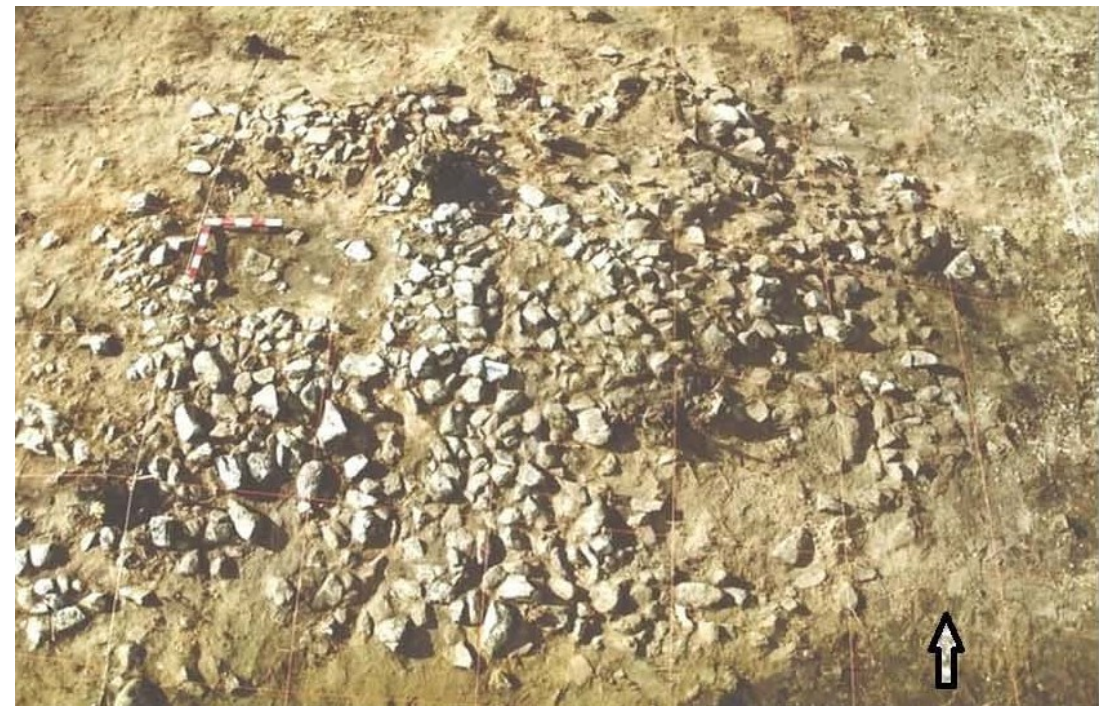

Fig. 3. Vale de Chão 1 após decapagem inicial (seg. Loureiro 2007). As réguas, que medem $50 \mathrm{~cm}$, assinalam a perturbação que existia no quadrante noroeste do tumulus.

Fig. 3. Vale de Chão 1 after the initial cleaning of the monument (after Loureiro 2007). The scale (which measure $50 \mathrm{~cm}$.) indicates that there was a disturbance in the Northwest sector of the tumulus.

A área central encontrava-se em parte perturbada devido a violações e ao crescimento de uma árvore (camada 2). Na base foram ainda detetadas duas camadas in situ (camadas 4a e 4b). Nesta área não foi localizada qualquer tipo de estrutura, em negativo ou em positivo, que indicasse a existência de uma câmara funerária bem individualizada. Também não foi identificado nenhum espessamento da couraça lítica.

Inserido no tumulus, a noroeste, identificouse uma estrutura retangular (estrutura 1) que foi construída posteriormente à construção do monumento. A estrutura 1 distribuía-se pelos quadrados G2, G3, G4 e, parcialmente, pelos quadrados F2 e F3. Apresentava planta sensivelmente subretangular, paredes grosseiramente oblíquas e base aplanada. Foi cortada nos sedimentos do tumulus e, em parte, no substrato rochoso. Pelo lado sul, onde corta as camadas $4 \mathrm{a}$ e $4 \mathrm{~b}$, parece ter sido delimitada por alguns blocos de granito. Tinha 1,80 $\mathrm{m}$ de comprimento por $0,40 \mathrm{~m}$ de largura média e $0,52 \mathrm{~m}$ de profundidade máxima. Orientava-se de sudoeste para nordeste. Por cima desta estrutura existiam terras similares às do tumulus, que terão aí sido depositadas após o enchimento da estrutura (Fig. 4).

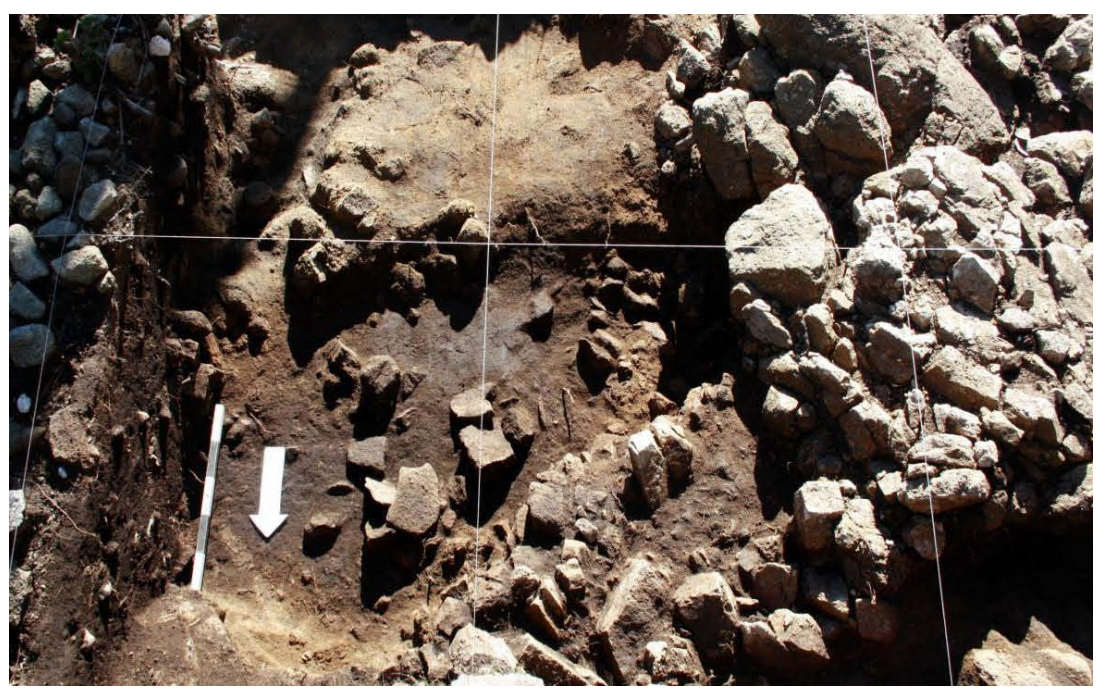

Fig. 4. Plano intermédio da estrutura 1 aberta no tumulus mais antigo (quadrados F2, F3, G2 e G3).

Fig. 4. Middle level of the structure 1 open in the oldest tumulus (squares F2, F3, G2 and G3). 


\subsection{Estratigrafia}

Registou-se a estratigrafia pelas diferentes áreas escavadas: as sondagens norte, sul, oeste e este; sondagem noroeste e área central.

\section{Sondagem norte}

Nesta sondagem foram apenas abertos os quadrados I5 e J5, o que nos possibilitou ter uma ideia aproximada do limite do tumulus. A estratigrafia aqui encontrada correspondia a três camadas cujas características se descrevem de seguida.

Camada 0: sedimentos limosos, de estrutura heterogénea, coloração castanho muito escuro, pouco compacto e com matéria orgânica (cinzas). Corresponde à camada humosa.

Camada 1: sedimentos de composição areno -limosa, de estrutura heterogénea, de coloração castanho escuro e de compacidade média. Corresponde, também, à camada humosa.

Camada 2: sedimentos de composição arenosa, de estrutura heterogénea, de coloração castanha clara e de compacidade reduzida. Corresponde a uma camada fora do monumento e sem vestígios arqueológicos.

\section{Sondagem sul}

Nesta área foram escavados os quadrados E4, D4, C4 e B4. Esta escavação possibilitou conhecer os limites do tumulus. Aqui foram individualizadas 3 camadas estratigráficas.

Camada 1: sedimentos de coloração castanho escuro, de composição areno-limosa, estrutura heterogénea e compacidade reduzida. Corresponde à camada humosa.

Camada 2: sedimentos de coloração castanho escuro, de composição areno-limosa estrutura heterógenea e compacidade média. Esta camada envolvia a couraça lítica na totalidade dos quadrados E4, D4, C4 e, parcialmente, no quadrado B4. Pode considerar-se o topo das terras do tumulus.

Camada 3: sedimentos castanho escuros a negros, de composição areno-limosa, estrutura heterogénea, algo compactos, com calhaus ${ }^{2}$ de granito local e raízes. Corresponde a terras do tumulus.

\section{Sondagem oeste}

Nesta sondagem foram abertos os quadrados E-1, E0, E1, E2 e E3 o que nos possibilitou conhecer a extremidade do tumulus pois o limite da couraça lítica só se manifestava até ao quadrado E1. Detetaram-se, também, três camadas estratigráficas (Fig. 5).

Camada 1: sedimentos de coloração castanho escuro, de composição areno-limosa, estrutura heterogéneas e compacidade reduzida. Corresponde à camada humosa.

Camada 1a: Sedimentos de coloração castanha escura, de composição areno-limosa, estrutura heterogénea e compacidade média.

Camada 2: sedimentos de coloração castanho escuro, de composição areno-limosa, estrutura heterogénea e compacidade média. Esta camada envolvia a couraça lítica nos quadrados E3, E2 e E1. Corresponde ao topo das terras do tumulus.

Camada 3: sedimentos constituídos por terras castanhas escuras a negro, de composição areno-limosa, estrutura heterogénea, algo compactos, com calhaus de granito local e raízes. Corresponde às terras depositadas para a construção do tumulus.

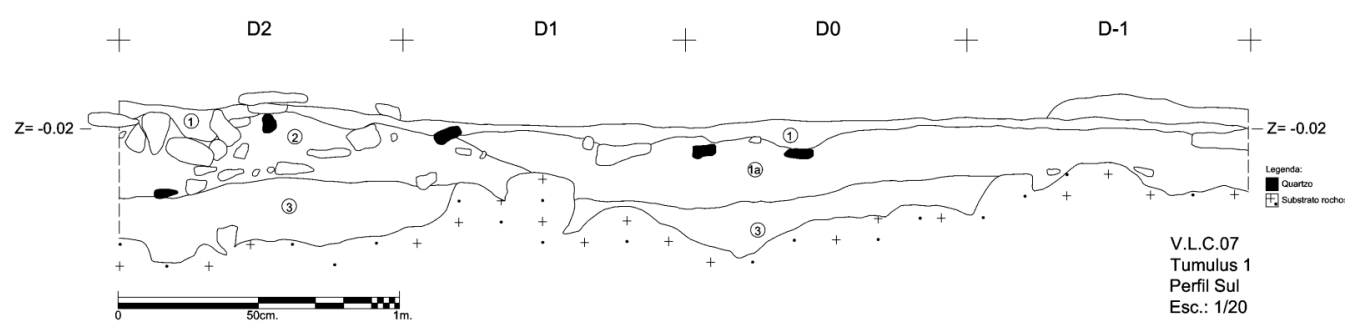

Fig. 5. Perfil sul da sondagem oeste. As pedras representadas a branco correspondem a granitos e as pintadas de negro, a quartzos.

Fig.5. West survey-pit of the south cross-section. The stones in white correspond to the granite pebbles and blocks: the stones in black correspond to quartz pebbles and blocks.

Usámos esta expressão quando nos referimos a fragmentos de rocha inferiores a 256 milímetros. Para os superiores foi usado o termo bloco. 


\section{Sondagem este}

Nesta sondagem foram abertos os quadrados: D7, E7, E8, E9, F7, F8, F9, G7, G8 e G9. Esta escavação possibilitou determinar o limite do tumulus. Aqui registámos cinco camadas estratigráficas.

Camada A (aterros): Sedimentos de coloração castanho-escuro, de composição arenosa, de estrutura muito heterogénea, pouco compactos (friável), com calhaus de pequena e média dimensão, raízes e carvões resultantes de incêndios recentes. Estes sedimentos são resultado dos trabalhos de regularização do terreno após a construção do poste de alta tensão que foi localizado nas imediações. Esta camada foi apenas identificada nos quadrados: E8, E9, F8, F9, G8 e G9.

Camada B (aterros): Sedimentos de coloração amarelada, composição arenosa, estrutura muito heterogénea e pouco compactos, com blocos de granito local de diferentes dimensões e algumas raízes. Correspondem a parte do enchimento da vala que envolve o poste de alta tensão. Esta camada surgia nos quadrados: E8, E9, F8 e F9.

Camada 1: Sedimentos de coloração amarelada, de composição arenosa, estrutura heterogénea e pouco compactos, com pequenos quartzos e de alguns calhaus e blocos graníticos, raízes e radículas. Corresponde à camada humosa.

Camada 2: Sedimentos de coloração acinzentada, homogénea, de composição arenolimosa, embora mais arenosa do que limosa, de estrutura heterogénea e medianamente compactos. Tinha calhaus de quartzo e calhaus e blocos graníticos. Esta camada envolvia a couraça lítica nos quadrados E8, F8 e G8. Corresponde ao topo das terras do tumulus.

Camada 3: Sedimentos de cor castanha escura a negro, composição areno-limosa, estrutura heterogénea, algo compactos, granulosos, com calhaus de granito local e raízes. Corresponde às terras do tumulus. Esta camada surgia nos quadrados E8, F8 e G8 e era similar à camada 3 das sondagens norte, sul e oeste.

\section{Sondagem no quadrante noroeste do} tumulus (Estrutura 1):

A escavação desta área permitiu identificar a estrutura 1. A estratigrafia aqui apresentada corresponde apenas ao seu enchimento (Fig. 6).

Camada 1: sedimentos de coloração castanho escuro, mais claras do que as terras do tumulus, de composição areno-limosa (mais limosa do que arenosa), medianamente compactos, com pequenas raízes e calhaus de granito local. Corresponde à última fase de colmatação da estrutura 1.

Camada 1a: sedimentos de coloração castanha mais escura do que a camada 1 , de composição areno-limosa (mais limosa do que arenosa), medianamente compactos. Camada de enchimento intermédia da estrutura 1.

Camada 1b: sedimentos de coloração castanha muito escura, de composição arenolimosa, sendo mais limosos do que os da camada 1a, medianamente compactos, com calhaus de granito local e muitos carvões que se distribuíam pela totalidade da camada. Em algumas áreas existiam pequenas concentrações de carvões. Pela sua disposição parece corresponder ao primeiro enchimento ocorrido posteriormente à abertura da estrutura.

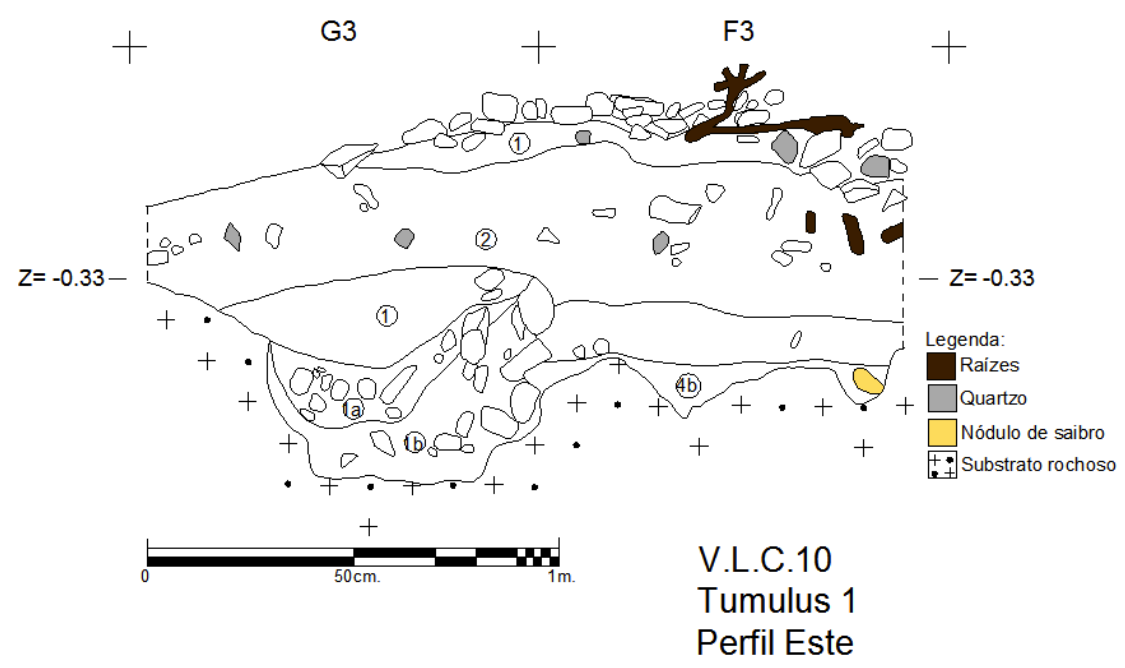

Fig. 6. Perfil este do enchimento da estrutura 1 nos quadrados G3 e F3. O último quadrado também abarca parte da área central do monumento.

Fig. 6. East cross-section of structure 1, on the squares G3 and F3. The latter square, also cover the central area of the monument. 


\section{Área central}

$\mathrm{Na}$ área central, onde se procurou uma estrutura de carácter funerário, foram intervencionados, após as duas campanhas arqueológicas, os quadrados E4, E5, F4, F5, G2, G3 e G4, num total de $14 \mathrm{~m}^{2}$. Aí não foi detetado qualquer tipo de estrutura em negativo ou em positivo que indicasse uma câmara funerária individualizada. A estratigrafia corresponde, em parte, à encontrada nas outras áreas escavadas do tumulus e a sedimentos resultantes da violação do monumento.

Camada 0: sedimentos de coloração castanha clara, composição areno-limosa, mas mais arenosos do que limosos, fraca compacidade, com raízes e carvões resultantes de incêndios recentes. Esta camada encontrava-se apenas no quadrado E3 e F3 e correspondia à camada humosa.

Camada 1: sedimentos de coloração castanha clara, composição areno-limosa, fraca compacidade, com raízes e carvões vegetais resultantes de incêndios recentes. Corresponde à camada humosa.

Camada 2: sedimentos de coloração castanha clara, composição areno-limosa, pouco compactos, revelando abundantes carvões dispersos, raízes e alguns calhaus e blocos de granito e de quartzo leitoso. Corresponde a terras do tumulus e à couraça que na zona central do monumento, estariam em deposição secundária devido a uma violação desta áreas manifestada pela presença de cerâmicas históricas e préhistóricas. Nestas circunstâncias pode considerar-se uma camada de violação. Em alguns quadrados sobrepunha-se sobre a camada 4a e, noutros, sobre a camada $4 b$.

Camada 3: sedimentos castanhos escuros a negros, algo compactos, de composição areno-limosa, com calhaus de granito e raízes que correspondem a terras do tumulus in situ. Encontra-se apenas em parte dos quadrados F5, E4 e E5, nas áreas não alteradas pela violação do monumento.

Camada 4a: sedimentos de coloração castanha clara, de composição areno-limosa, medianamente compactos, com alguns calhaus, raízes e carvões de dimensão reduzida. Esta camada era pouco espessa e estava presente nos quadrados F3, F4 e parcialmente no E4. Dispunha-se de forma horizontal e aparentava estar in situ.

Camada 4b: sedimentos de coloração castanha mais clara do que a camada anterior embora no quadrado F5 existisse uma mancha de tonalidade um pouco mais escura. A sua composição era arenosa, pouco compacta e continha radículas e raros carvões dispersos. Esta camada estava presente na quase totalidade dos quadrados F4 e F5, em boa parte do quadrado G3 e, parcialmente, nos quadrados E4, E5 e F3. Ficava imediatamente por cima da arena granítica. Aparentava estar in situ. Pensamos que poderá corresponde à base da camada $4 \mathrm{a}$ assumindo uma tonalidade mais clara por estar próxima da arena granítica.

Estas duas camadas parecem corresponder ao que restou das ritos originais praticadas nesta área do monumento.

\subsection{Material arqueológico exumado}

Na zona central, na camada 2, foram exumadas cerâmicas romanas ou medievais associadas a fragmentos de panças de recipientes pré-históricos de pequenas dimensões, segundo os critérios de Brudenell e Cooper (2008) (Tab. 1).

$\mathrm{Na}$ camada $4 \mathrm{~b}$ ocorreram 3 fragmentos de panças pré-históricas, de fabrico manual, com pasta arenosa, acabamento alisado e cozeduras redutoras e oxidantes (Tab. 2).

Tabela 1. Tipo de fabrico da cerâmica exumada

Table 1. Manufacture types of the ceramic sherds exhumed

\begin{tabular}{|c|c|c|}
\hline Tipo de fabrico & Camada 2 & Camada 4b \\
\hline Cerâmica a torno & 16 & 0 \\
\hline Cerâmica manual & 3 & 3 \\
\hline Total & 19 & 3 \\
\hline
\end{tabular}

Tabela 2. Características dos fragmentos cerâmicos da camada $4 \mathrm{~b}$

Table 2. Characteristics of ceramic fragments unheard of the layer $4 \mathrm{~b}$

\begin{tabular}{|l|l|l|}
\hline Contexto & Características & Localização \\
\hline Quadrado F 5 & $\begin{array}{l}\text { Fragmento de pança de reduzidas dimensões, de fabrico } \\
\text { manual, revelando uma pasta arenosa com grãos de areia de } \\
\text { média dimensão, coloração cinzento claro e cozedura redutora. }\end{array}$ & X: 0.20; Y: 0.78 \\
\hline Quadrado F 5 & $\begin{array}{l}\text { Fragmento de pança de reduzidas dimensões, de fabrico } \\
\text { manual, revelando uma pasta arenosa com grãos de areia de } \\
\text { média dimensão, coloração cinzento claro e cozedura redutora. }\end{array}$ & X:20; Y: 0.78 \\
\hline Quadrado F 4 & $\begin{array}{l}\text { Fragmento de pança de reduzidas dimensões, de fabrico aparen- } \\
\text { temente manual, revelando uma pasta arenosa com grãos de } \\
\text { areia de média dimensão, coloração castanho claro e cozedura } \\
\text { oxidante. }\end{array}$ & \\
\hline
\end{tabular}


Nas terras do tumulus, na base da camada 3, foi encontrado um movente de um moinho manual de pequenas dimensões, em granito. Este artefacto tanto poderá ter sido transportado no momento em que se ergueu este monumento, como ser de cronologia anterior tendo em conta que se detetou um valado neolítico, selado, pela construção desta estrutura ${ }^{3}$.

\section{DATAÇÕES PELO RADIOCARBONO}

Com o objetivo de datar o monumento enviámos para o laboratório da University of Arizona - NSF Arizona AMS Facility, Estados Unidos da América, carvões vegetais de espécie indeterminada, provenientes da camada 4 b, ou seja, da última camada da área central do monumento e que nos parecia estar in situ. Dada a reduzida quantidade de carvão existente na camada, esta foi aproveitada na totalidade para a análise radiométrica. A datação obtida corresponde ao primeiro quartel do $1^{\circ}$ quartel do II milénio cal. BC e permite-nos inserir, pelo menos hipoteticamente, a construção deste monumento no Bronze Inicial (Tab. 3).

$\mathrm{Na}$ tentativa de datarmos a estrutura 1 , mandámos para o mesmo laboratório uma amostra de carvão de carvalho de espécie não determinada, proveniente da camada $1 \mathrm{~b}$. A datação obtida permite-nos colocar a hipótese desta estrutura ter sido construída a partir do $3^{\circ}$ quartel do II milénio cal. BC, isto é, do Bronze Médio (Tab. 3).

Ambas as datações foram obtidas por AMS e calibradas com o programa Oxcal 4.1.7 (BRONK RAMSEY 2010), usando a curva de calibração InCall13 (REIMER et al. 2013).

Tabela 3. Datas de radiocarbono

Table 3. Radiocarbon dates

\begin{tabular}{|c|c|c|c|c|}
\hline Ref. Lab. & Data BP & Contexto & Cal. BC (1 sigma) & Cal. BC (2 sigma) \\
\hline AA 89664 & $3538 \pm 42$ & $\begin{array}{l}\text { Área central } \\
\text { (cam. 4b) }\end{array}$ & $\begin{array}{l}1940-1871(37,7 \%) \\
1846-1812(17,2 \%) \\
1803-1776(13,3 \%)\end{array}$ & $\begin{array}{l}2009-2002(1 \%) \\
1976-1749(94.4 \%)\end{array}$ \\
\hline AA 89665 & $3156 \pm 41$ & $\begin{array}{l}\text { Estrutura } 1 \\
\text { (camada 1b) }\end{array}$ & $\begin{array}{l}1493-1475(12,8 \%) \\
1461-1402(55,4 \%)\end{array}$ & $\begin{array}{l}1516-1373(90,8 \%) \\
1342-1318(4,6 \%)\end{array}$ \\
\hline
\end{tabular}

\section{DISCUSS ÃO DOS RESULTADOS E INTERPRE- TAÇÕES}

Os trabalhos arqueológicos efetuados em Vale de Chão 1, possibilitaram a descoberta de um monumento funerário, possivelmente_construído durante o Bronze Inicial, de planta sensivelmente circular e com cerca de $7 \mathrm{~m}$ de diâmetro e de menos de $1 \mathrm{~m}$ de altura máxima.

O tumulus foi construído por sedimentos, por vezes, pouco espessos (camada 3) que assentavam quer diretamente sobre o substrato rochoso, quer sobre a arena granítica ${ }^{4}$. O seu topo foi coberto por uma couraça lítica constituída por calhaus e blocos de granito porfiróide e por calhaus de quartzo leitoso (camada 2), de origem local, embora dispostos de forma aparentemente aleatória (Fig. 2).

Apesar das suas dimensões relativamente pequenas, este monumento foi construído com a clara preocupação de se tornar visível para os vivos e de marcar um espaço que se pensa estar associado às práticas funerárias. A sua visualização é-lhe conferida pela quantidade de quartzo leitoso utilizado.

A área central, parcialmente violada (camadas
1 e 2), não apresentava qualquer tipo de estrutura pétrea ou em negativo, ao nível das camadas preservadas (camadas $4 \mathrm{a}$ e $4 \mathrm{~b}$ ), pelo que nos questionamos se a deposição do corpo ou de eventuais cinzas se poderia ter efetuado diretamente sobre o solo ou sobre qualquer estrutura em material perecível. Seja como for o rito aqui praticado ter-se-á feito acompanhar de alguns recipientes cerâmicos de pequeno tamanho, tendo em conta a variedade e espessura das pastas, bem como das dimensões dos fragmentos cerâmicos pré-históricos encontrados nas terras da violação do monumento (camada 2).

Apesar de não termos analisado os carvões vegetais e de não sabermos se são provenientes de pequenos ramos ou troncos, aceitamos a data de radiocarbono para a construção de Vale de Chão 1, tendo presente o grande número de monumentos sob tumuli que se conhecem para o Noroeste Peninsular. Sem carácter de exaustividade, referimos, para este período, os monumentos de Monte da Deva 5, em Gijón (Astúrias); Illade 3 e Reboredo 1, As Pontes (Galiza); Meninas do Crasto 4 e Outeiro de Gregos 1, em Baião e Serra da Muna 1 e 2, em Viseu. Referimos, ainda, o de Outeiro de Gregos 5,

Este assunto está a ser tratado na dissertação de mestrado do autor que se pretende entregar em breve.

4 Não foi detetado qualquer solo antigo. Agradecemos à Prof ${ }^{a}$ Doutora Isabel Caetano Alves do Departamento de Ciências da Terra da Universidade do Minho, em Braga, as várias visitas à escavação e a troca de impressões sobre a estratigrafia do monumento. 
em Baião, que apesar de estar datado do Bronze Médio também não apresenta "qualquer estrutura interna” (JoRGE et al. 1988: 96).

Posteriormente, já durante o Bronze Médio, entre os fins do séc. XVI e os inícios do séc. XIV AC, ou em fase posterior dado o possível efeito de envelhecimento do resultado de radiocarbono resultante do tipo de carvão analisado, o monumento de Vale de Chão 1 terá sido reutilizado. No sector noroeste do tumulus foi aberta uma estrutura sub retangular de 1,80 $\mathrm{m}$ de comprimento por $0,40 \mathrm{~m}$ de largura média e 0,52 $\mathrm{m}$ de profundidade máxima. Pela sua forma e dimensões, esta estrutura assemelha-se a uma sepultura plana, relativamente abundantes no Noroeste de Portugal, como é o caso da necrópole de Cimalha, em Felgueiras (ALMEIDA \& FERNANDES 2008; ALMEIDA et al. 2008), da necrópole do Pego, Braga (SAMPAIO \& BETTENCOURT, 2014), da necrópole do Tapado da Caldeira, Baião (JORGE 1980a, 1980b). Mas se as suas dimensões permitem pensar que esta estrutura teria servido para uma eventual inumação individual as características e disposição do seu primeiro enchimento (camada 1b), com inúmeros carvões, faz-nos colocar a hipótese de que teria existido uma qualquer cerimónia onde o fogo foi importante (cremação?), tendo, posteriormente, os restos sido depositados no interior da estrutura.

A reutilização de um monumento sob tumulus do Bronze Inicial, durante o Bronze Médio, é uma prática para a qual não conhecemos paralelos no Noroeste português, embora em Outeiro de Gregos 1, do Bronze Inicial, tenha sido anexada uma estrutura do Bronze Médio (JORGE 1980) algo atípica, o que mostra que os lugares dos mortos podem manter-se ativos por muitas centenas de anos.

Finalmente, no período romano ou nos inícios da Idade Média, de acordo com alguns materiais cerâmicos encontrados, deu-se a violação da área central do monumento.

Nesta ótica, o lugar de Vale de Chão foi alvo de ocupações e/ou revisitações na longa duração, pelo menos desde o Neolítico Médio/Final ${ }^{6}$ até ao tardo romano ou Alto-Medieval.

\section{AGRADECIMENTOS}

Este trabalho foi desenvolvido no âmbito do projeto de dissertação de mestrado do signatário intitulado " $O$ povoamento pré-histórico da Serra do Carvalho. Estudo a partir dos tumuli 1 e 2 de Vale de Chãos, Braga”, que, por sua vez, se insere na tarefa 4 do projeto Espaços Naturais, Arquiteturas, Arte rupestre e Deposições na Pré-história Recente da Fachada Ocidental do Centro e Norte Português: das Ações aos Significados - ENARDAS (PTDC/HISARQ/112983/2009), financiado pelo Programa Operacional Temático Fatores de Competitividade (COMPETE) e comparticipados pelo Fundo Comunitário Europeu FEDER.

$\mathrm{O}$ autor agradece a Luís Filipe Loureiro os dados disponibilizados relativos aos seus trabalhos de campo; ao Doutor Pedro Pimenta Simões a classificação litológica dos constituintes do monumento; à Doutora Isabel Caetano Alves, o acompanhamento durante as escavações e os esclarecimentos relacionados com a sedimentologia do local e a Filipe Pereira o trabalho de cartografia.

\section{BIBLIOGRAFIA}

AlmeIDA, C.A.; ALMEIDA, P.B. \& FeRnANDES, F. 2008. O povoado do Bronze Final da Cimalha, Sernande, Felgueiras. Relatório de Intervenção Arqueológica. Felgueiras: Câmara Municipal.

AlmeidA, P.B. \& Fernandes, F. 2008. O povoado da Idade do Bronze da Cimalha. Actas do I Encontro de Terras de Sousa (Lousada, 2007). [Oppidum, Número Especial]: 29-44.

BeTtEnCOURT, A.M.S. 2010. La Edad del Bronce en el Noroeste de la Península Ibérica: una análisis a partir de las prácticas funerarias, Trabajos de Prehistoria, 67 (1): 139-173.

BRONK RaMSEY, C. 2010. OxCal Program, v. 4.1.7, Radiocarbon Accelerator Unit, University of Oxford, UK; programa acessível no site http://c14.arch.ox.ac.uk/embed.php? File $=$ oxcal.html (último acesso em Dezembro de 2013).

BRUdENELl, M. \& COOPER A. 2008. Post-middenism: depositional histories on Later Bronze Age settlements at broom, Bedfordshire. Oxford Journal of Archaeology, 27: 15-36.

FERREIRA, N.; DiAS, G. \& BRAGA, M.A.S. 2000a. Carta Geológica de Portugal na escala de 1/50000, folha 5D-Braga, Lisboa: Instituto Geológico e Mineiro.

FERreirA, N.; DiAS, G.; MeIRELES, C.A.P. \& BraGA. M.A.S. 2000b. Noticia Explicativa da folha 5D-Braga da Carta Geológica de Portugal na escala de 1/50000. Lisboa: Instituto Geológico e Mineiro.

JoRGE, S.O. 1980a. A necrópole do Tapado da Caldeira-Baião. Arqueologia, 2: 36-44.

JORGE, S.O. 1980b. A estação arqueológica do Tapado da Caldeira, Baião. Portugalia 1 (Nova série): 29-50.

JORGE, V.O. 1980. Escavação da Mamoa 1 de Outeiro de Gregos, Serra da Aboboreira, Baião. Portugalia 1 (Nova série): 9-28.

Jorge, V.O.; AlONSO, F.; DELIBRIAS, G., 1988.Novas datas de Carbono 14 para mamoas da Serra da Aboboreira. Arqueologia, 18: 95-98.

REIMER P.J.; BARD, E.; BAYLISS, A.; BECK, J.W.; BLACKWELL, P.G.; RAMSEY, C.B.; BUCK, C.E.; CHENG, H.; EDWARDS, R.L.; FRIEDRICH, M.; GROOTES, P.M.; GUILDERSON, T.P.; HAFLIDASON, H.; HAJDAS, I.; HATTÉ, C.; HeATON, T.J.; HofFMANN, D.L.; HogG, A.G.; HugHEN, K.A.; KAISER, K.F.; KROMER, B.; MANNING, S.W.; NIU, M.; REIMER, R.W.; RICHARDS, D.A.; SCOTT, E.M.; SOUTHON, J.R.; STAFF, R.A.; TURNEY, C.S.M. \& VAN DER PLICHT, J. 2013. IntCal13 and Marine13 Radiocarbon Age Calibration Curves 0-50,000 Years cal BP. Radiocarbon 55 (4): 1869-1887. Doi: 10.2458/azu_js_rc.55.16947.

SAMPAIO, H.A. \& BETTENCOURT, A.M.S. 2014. Between the valley and the hilltop. Discoursing on the spatial importance of Pego's Bronze Age necropolis, Braga (Northwest of Portugal)". Estudos do Quaternário 10: 45-57. 